\title{
Hormone replacement therapy and the risk of subarachnoid hemorrhage in postmenopausal women
}

\author{
Adnan I. Qureshi, MD, Ahmed A. Malik, MD, Omar Saeed, MD, Archie Defillo, MD, \\ Gregory T. Sherr, MD, and M. Fareed K. Suri, MD
}

Zeenat Qureshi Stroke Institute, St. Cloud, Minnesota

OBJECTIVE The incidence of subarachnoid hemorrhage (SAH) increases after menopause. Anecdotal data suggest that hormone replacement therapy (HRT) may reduce the rate of SAH and aneurysm formation in women. The goal of this study was to determine the effect of HRT on occurrence of SAH in a large prospective cohort of postmenopausal women.

\begin{abstract}
METHODS The data were analyzed for 93,676 women 50-79 years of age who were enrolled in the observational arm of the Women's Health Initiative Study. The effect of HRT on risk of SAH was determined over a period of $12 \pm 1$ years (mean \pm SD) using Cox proportional hazards analysis after adjusting for potential confounders. Additional analysis was performed to identify the risk associated with "estrogen only" and "estrogen and progesterone" HRT among women.

RESULTS Of the 93,676 participants, $114(0.1 \%)$ developed SAH during the follow-up period. The rate of SAH was higher among women on active HRT compared with those without HRT used $(0.14 \%$ vs $0.11 \%$, absolute difference $0.03 \%$, $p<0.0001)$. In unadjusted analysis, participants who reported active use of HRT were $60 \%$ more likely to suffer an SAH (RR 1.6, 95\% Cl 1.1-2.3). Compared with women without HRT use, the risk of SAH continued to be higher among women reporting active use of HRT (RR 1.5, 95\% Cl 1.0-2.2) after adjusting for age, systolic blood pressure, cigarette smoking, alcohol consumption, body mass index, race/ethnicity, diabetes, and cardiovascular disease. The risk of SAH was nonsignificantly higher among women on "estrogen only" HRT (RR 1.4, 95\% Cl 0.91-2.0) than "estrogen and progesterone" HRT (RR 1.2, 95\% Cl 0.8-2.1) after adjusting for the above-mentioned confounders.
\end{abstract}

CONCLUSIONS Postmenopausal women, particularly those at risk for SAH due to presence of unruptured aneurysms, family history, or cardiovascular risk factors, should be counseled against use of HRT.

http://thejns.org/doi/abs/10.3171/2014.12.JNS142329

KEY WORDS hormone replacement therapy; subarachnoid hemorrhage; postmenopausal women; estrogen replacement; vascular disorders; intracranial aneurysm

$\mathrm{T}$ HE risk of intracranial aneurysm formation and subarachnoid hemorrhage (SAH) is higher in postmenopausal women compared with premenopausal women. ${ }^{8,13,18,19,28}$ Reduced levels of estrogen in postmenopausal women may increase the risk of aneurysm formation and rupture by reduction in collagen and elastin content and reduced elasticity of arterial walls. ${ }^{3}$ In an experimental intracranial aneurysm mouse model, estrogen prevented aneurysmal rupture in ovariectomized mice. ${ }^{30}$ The protective effect of estrogen seemed to occur through activation of estrogen receptor- $\beta$, a predominant subtype of estrogen receptor in human intracranial aneurysms and cerebral arteries. Hormone replacement therapy (HRT) was associated with reduced risk of spontaneous $\mathrm{SAH}$ in postmenopausal women in most ${ }^{19,22}$ but not all case control studies. ${ }^{25}$ The Women's Health Initiative (WHI) randomized trial ${ }^{33}$ assessed the effect of estrogen plus progestin on ischemic and hemorrhagic stroke in 608 women 5079 years of age with an average follow-up of 5.6 years. There was a nonsignificant protective effect on hemorrhagic stroke (HR $0.82,95 \%$ CI 0.43-1.56). However, the study was underpowered because there were only $10 \mathrm{SAH}$ events among the randomized patients. A meta-analysis ${ }^{24}$ found a small nonsignificant protective effect of HRT on risk of SAH (HR 0.8, 95\% CI 0.57-1.04).

We performed this study to determine the effect of

ABBREVIATIONS HRT = hormone replacement therapy; RR = relative risk; $S A H=$ subarachnoid hemorrhage; $S E=$ standard error; WHI = Women's Health Initiative . SUBMITTED October 11,2014. ACCEPTED December 12, 2014.

INCLUDE WHEN CITING Published online July 10, 2015; DOI: 10.3171/2014.12.JNS142329.

DISCLOSURE The authors report no conflict of interest concerning the materials or methods used in this study or the findings specified in this paper. 
HRT on risk of SAH in a large prospective cohort of postmenopausal women.

\section{Methods}

We analyzed the data for 93,676 women 50-79 years of age who were enrolled in the observational arm of the WHI study. ${ }^{2,15}$ Briefly, women who were screened for the clinical trial but proved to be ineligible or unwilling to be randomized were offered the opportunity to enroll in the observational arm. Study participants were enrolled at 40 centers throughout the US between October 1, 1993, and December 31, 1998. Potential subjects were excluded if they did not plan to reside in the area for at least 3 years, had medical conditions predictive of survival less than 3 years, or had complicating conditions such as alcoholism, drug dependency, or dementia. All participants provided informed consent using materials approved by Institutional Review Boards at each center. Demographic and risk exposure data, as well as data regarding family and medical history, were obtained by self-report using standardized questionnaires at baseline assessment. Certified staff took physical measurements, including blood pressure, height and weight, and blood samples at the clinic visit. ${ }^{34}$ For postmenopausal hormone treatment, detailed information was obtained on the preparation, estrogen and progesterone dose, schedule, and route of administration.

Recruitment for the observational study was completed in 1998 and participants were followed for 8-12 years. Annual, mailed follow-up forms updated information on HRT and other selected risk factor information and structured initial reporting of clinical events.? Specific details of illnesses and stroke hospitalizations were obtained as needed via a standardized questionnaire administered by phone, in-person interview, or self-completed form. Portions of the medical record (discharge summary and results of relevant diagnostic and laboratory tests) were requested, assembled, and provided to the designated local adjudicator, who adjudicated the event. A fraction of the stroke events in the observational study were reviewed by central neurologists for quality control.? In a previous analysis of the WHI clinical trial, $94.5 \%$ of stroke events identified by the local adjudicator were confirmed on central review, while $93.8 \%$ of centrally adjudicated strokes had been classified as strokes by local adjudicators. ${ }^{33}$ Following notice of a participant's death, information was obtained on any outcomes occurring between the participant's last routine contact and her date of death. To ascertain survival and cause of death for all WHI participants, data linkage with the National Death Index of the National Center for Health Statistics was used. WHI participants who are lost to follow-up or who are known to be dead were matched to the National Death Index to search for otherwise unreported deaths and to ascertain causes of death.

\section{Statistical Analysis}

Because the interval of follow-up varied among study participants, Cox proportional hazards analysis was used to estimate the relative risk (RR) for SAH using IBM SPSS statistical software (IBM Corp.). We evaluated the RR for any HRT use (previous or active at time of baseline assessment), active use at baseline assessment, and type of replacement therapy ("estrogen only" vs "estrogen and progesterone"). The potential confounders were identified from previous reports ${ }^{1,3}$ and from univariate analysis of demographic and clinical variables between women who did or did not develop SAH. We used chi-square and ANOVA for categorical and continuous variables, respectively. The multivariate adjusted Cox proportional hazards model adjusted for differences in age, sex, race/ethnicity (African American, white, others), systolic blood pressure (continuous variable), body mass index ( $\mathrm{cm} / \mathrm{kg}$ [continuous variable]), cigarette smoking (never, former, current), alcohol consumption ( $\geq 7$ drinks per week, 1 to $<7$ drinks per week, and other [nondrinker, past drinker, $<1$ drink per month, or $<1$ drink per week]), diabetes mellitus, and cardiovascular disease that were significantly different in univariate analysis. We calculated $95 \%$ CIs using a Taylor series approximation for the standard error (SE) of the RR. In another analysis, the adjusted RR of SAH was compared between participants who had never used HRT compared with those who had used HRT either in the past or were actively using HRT.

\section{Results}

Of 93,676 participants, a total of $114(0.1 \%)$ developed SAH during the follow-up period of $12 \pm 1$ (mean $\pm \mathrm{SD}$ ) years. HRT was being used at baseline assessment by 41,630 of the 93,676 participants. The age at baseline assessment (mean \pm SD) was significantly lower among participants who were actively using HRT compared with those who did not $(62.0 \pm 7.1$ years vs $64.9 \pm 7.3$ years, $p$ $<0.0001$ ) (Table 1). The proportion of participants 70-79 years of age was lower among those who were actively using HRT (16.9\% vs 30.2\%, p < 0.0001). The body mass index (mean $\pm \mathrm{SD}$ ) was lower among participants who were actively using HRT $(26.5 \pm 5.2$ vs $27.9 \pm 6.0, p<$ $0.0001)$. The initial systolic blood pressure (mean \pm SD) was significantly lower among participants who were actively using HRT compared with those who did not (125.5 \pm 17.5 versus $128.1 \pm 18.3, p<0.0001)$. There was a higher proportion of participants with diabetes mellitus $(5.6 \%$ vs $2.8 \%, \mathrm{p}<0.0001)$ and cardiovascular disease $(19.8 \%$ vs $17.3 \%, \mathrm{p}<0.0001)$ among those who were not actively using HRT compared with those who were. There was a higher proportion of participants who were actively using HRT who admitted to having 7 or more drinks per week $(12.9 \%$ vs $12.2 \%, p=0.007)$. The proportion of participants who were either past or active cigarette smokers was higher among those who were actively using HRT (49.6\% vs $47.3 \%$, $\mathrm{p}<0.0001$ ). The proportion of patients with previous use of HRT was similar among those who were or were not actively using HRT (18.4\% vs $14.9 \%, \mathrm{p}=0.3)$.

The proportion of participants who died during follow-up was significantly higher among those who developed SAH $(44.2 \%$ vs $11.6 \%, \mathrm{p}<0.0001)$. The 10 -year SAH-free survival was significantly lower among persons who reported active use of HRT $(69.7 \%, 95 \%$ CI $69.6 \%-69.8 \%)$ or estrogen-only HRT $(68.7 \%, 95 \%$ CI $68.6 \%-68.8 \%$ ) compared with those who did not report active use of any replacement therapy $(76.3 \%, 95 \%$ CI 76.2\%-76.4\%; Fig. 1). 
TABLE 1. Baseline characteristics for postmenopausal women according to active use of HRT: WHI Observational Study*

\begin{tabular}{|c|c|c|c|}
\hline \multirow[b]{2}{*}{ Baseline Characteristics } & \multicolumn{2}{|c|}{ No. of Participants (\%) } & \multirow[b]{2}{*}{ p Value } \\
\hline & Women Actively Using HRT & Women Not Actively Using HRT & \\
\hline Overall no. of participants & 41,630 & 52,046 & \\
\hline Mean age in yrs & $62.0 \pm 7.1$ & $64.9 \pm 7.3$ & $<0.0001$ \\
\hline Age in yrs & & & $<0.0001$ \\
\hline $50-54$ & $7122(17.1)$ & $5260(10.1)$ & \\
\hline $55-59$ & $9317(22.4)$ & $8008(15.4)$ & \\
\hline $60-69$ & $18,152(43.6)$ & $23,044(44.3)$ & \\
\hline $70-79$ & $7039(16.9)$ & $15,734(30.2)$ & \\
\hline Body mass index, $\mathrm{cm} / \mathrm{kg}$ (mean $\pm \mathrm{SD}$ ) & $26.5 \pm 5.2$ & $27.9 \pm 6.0$ & $<0.0001$ \\
\hline Body mass index categorical, cm/kg & & & $<0.0001$ \\
\hline Underweight $(<18.5)$ & $351(0.8)$ & $476(0.9)$ & \\
\hline Normal (18.5-24.9) & $18,553(44.6)$ & $18,422(35.4)$ & \\
\hline Overweight (25.0-29.9) & $13,929(33.5)$ & $17,563(33.7)$ & \\
\hline Obesity I (30.0-34.9) & $5634(13.5)$ & $8982(17.3)$ & \\
\hline Obesity II (35.0-39.9) & $1859(4.5)$ & $3594(6.9)$ & \\
\hline Extreme obesity III ( $\geq 40)$ & $924(2.2)$ & $2376(4.6)$ & \\
\hline Race/ethnicity & & & $<0.0001$ \\
\hline White (not of Hispanic origin) & $5479(13.1)$ & $2156(4.1)$ & \\
\hline African American & $36,001(86.5)$ & $42,015(80.7)$ & \\
\hline Others & $402(1.0)$ & $657(1.3)$ & \\
\hline Systolic blood pressure, $\mathrm{mm} \mathrm{Hg}$ (mean $\pm \mathrm{SD}$ ) & $125.5 \pm 17.5$ & $128.1 \pm 18.3$ & $<0.0001$ \\
\hline \multicolumn{4}{|l|}{ Medical comorbidities } \\
\hline Diabetes mellitus & $1166(2.8)$ & $2898(5.6)$ & $<0.0001$ \\
\hline Myocardial infarction & $789(1.9)$ & $1517(2.9)$ & $<0.0001$ \\
\hline Elevated cholesterol & $5474(13.1)$ & $8299(15.9)$ & $<0.0001$ \\
\hline Congestive heart failure & $300(0.7)$ & $721(1.4)$ & $<0.0001$ \\
\hline Cardiovascular disease & $7206(17.3)$ & $10,317(19.8)$ & $<0.0001$ \\
\hline Alcohol use & & & 0.007 \\
\hline$\geq 7$ drinks per wk & $5355(12.9)$ & $6349(12.2)$ & \\
\hline 1 to $<7$ drinks per wk & $10,574(25.4)$ & $13,250(25.5)$ & \\
\hline $\begin{array}{l}\text { Others (nondrinker, past drinker, <1 drink per mo, } \\
\quad<1 \text { drink per wk) }\end{array}$ & $25,386(61.0)$ & $32,077(61.6)$ & \\
\hline Cigarette smoking & & & $<0.0001$ \\
\hline Never smoked & $20,426(49.1)$ & 26,595 (51.1) & \\
\hline Former smoker & $18,425(44.3)$ & $21,089(40.5)$ & \\
\hline Current smoker & $2227(5.3)$ & $3563(6.8)$ & \\
\hline
\end{tabular}

In the unadjusted analysis, participants who reported active use of HRT were $60 \%$ more likely to suffer an SAH (RR 1.6, 95\% CI 1.1-2.3) (Table 2). Adjustment for all potential confounders did affect the RR of SAH associated with active use of HRT. In the multivariate adjusted analyses, participants who reported active use of HRT were $50 \%$ more likely than those without HRT to suffer an SAH (RR 1.5, 95\% CI 1.0-2.2). The risk of SAH was higher among women on "estrogen only" HRT (RR 1.4, 95\% CI 0.91-2.0) than "estrogen and progesterone" HRT (RR 1.2, 95\% CI 0.8-2.1). In another analysis, the RR of SAH was significantly lower among participants who had never used HRT compared with those who had used HRT either in the past or were actively using HRT (HR 0.58, 95\% CI 0.4-0.9).

\section{Discussion}

Use of HRT continues to be prevalent among postmenopausal women, with a lifetime prevalence of HRT ranging from $26.8 \%$ to $48 \% .{ }^{17}$ Active use is reported by $24 \% \%^{5}-32 \% 17$ of postmenopausal women. The prevalence is higher among younger postmenopausal women. 5,17,20 The prevalence is either similar or lower among women who develop SAH. In a population-based study within Kings County, Washington, $25 \%$ of women with SAH were ei- 


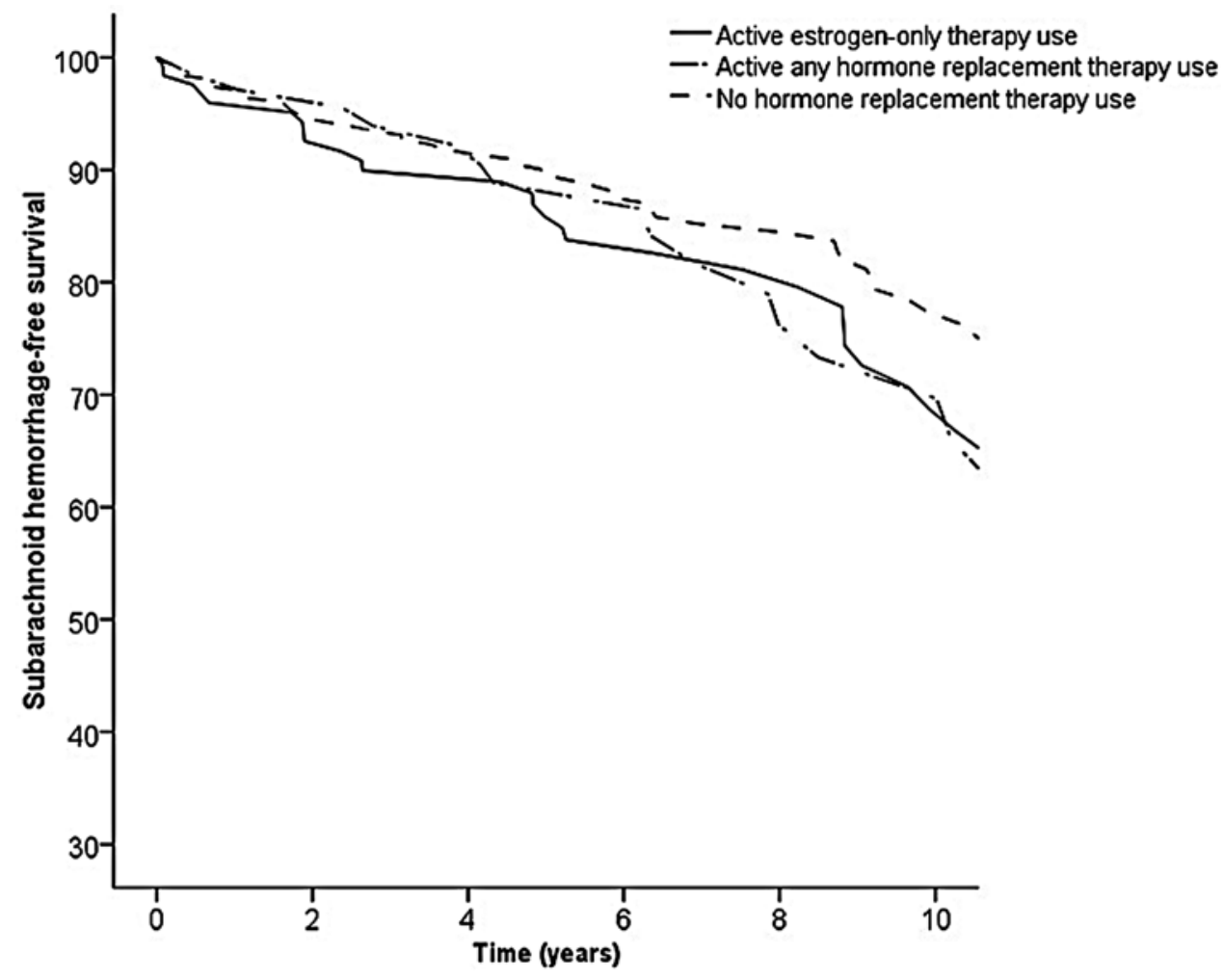

FIG. 1. Comparison of 10-year SAH-free survival in patients with active estrogen-only HRT, active any HRT, and no use of HRT.

ther actively using or had used HRT. ${ }^{19}$ In the Australasian Cooperative Research on Subarachnoid Hemorrhage Study (ACROSS), 21\% of women with SAH had used or were actively using HRT. ${ }^{22}$ In an analysis of the Danish National Patient Register, 35\% of Danish women 45-64 years of age with SAH had either used or were actively using HRT. ${ }^{25}$

We found that the risk of $\mathrm{SAH}$ was 1.5 -fold higher among postmenopausal women on HRT after adjusting for potential confounders. Both "estrogen only" and "estrogen and progesterone" HRT were associated with an increased risk for $\mathrm{SAH}$. Our results may be different from results of some of the previous case control studies..$^{19,22}$ The increased risk in postmenopausal women is similar to the increased risk observed with oral contraceptive use in premenopausal women. ${ }^{11}$ There was a $40 \%$ higher risk of SAH among women who used oral contraceptives in previous analyses. ${ }^{11}$ High-estrogen oral contraceptives appeared to impart a greater risk than low-dose preparations in studies that controlled for smoking, but the difference was not significant. The combination of cigarette smoking and oral contraceptive use resulted in a synergistic increase in risk of SAH. ${ }^{26}$ The unadjusted magnitude of absolute difference in rates of $\mathrm{SAH}$ between women on

TABLE 2. Multivariate adjusted risk of SAH in postmenopausal women using HRT: WHI Observational Study

\begin{tabular}{|c|c|c|c|c|c|}
\hline Parameter & $\begin{array}{l}\text { Total No. } \\
\text { of Pts }\end{array}$ & $\begin{array}{l}\text { No. of SAH } \\
\text { Cases }\end{array}$ & $\begin{array}{l}\text { Rate Per } \\
100 \text { Persons }\end{array}$ & $\begin{array}{l}\text { Unadjusted } \\
\text { RR }(95 \% \mathrm{Cl})\end{array}$ & $\begin{array}{l}\text { Adjusted RR* } \\
\quad(95 \% \mathrm{Cl})\end{array}$ \\
\hline \multicolumn{6}{|l|}{ Active use at baseline evaluation } \\
\hline Nonactive user of HRT & 38,024 & 35 & 0.09 & Reference & Reference \\
\hline Active user of any HRT & 41,630 & 58 & 0.1 & $1.6(1.1-2.3)$ & $1.5(1.0-2.2)$ \\
\hline Active user of "estrogen only" replacement therapy & 23,290 & 37 & 0.2 & $1.4(0.94-2.1)$ & $1.4(0.91-2.0)$ \\
\hline $\begin{array}{l}\text { Active user of "estrogen and progesterone" combi- } \\
\text { nation replacement therapy }\end{array}$ & 18,340 & 21 & 0.1 & $1.4(0.9-2.2)$ & $1.2(0.8-2.1)$ \\
\hline \multicolumn{6}{|l|}{ Any lifetime use } \\
\hline Used HRT at any time (past or active) & 55,488 & 79 & 0.1 & Reference & Reference \\
\hline Never used HRT & 38,024 & 35 & 0.09 & $0.57(0.4-0.9)$ & $0.58(0.4-0.9)$ \\
\hline
\end{tabular}

pts = patients.

* Adjusted for age, systolic blood pressure, cigarette smoking, alcohol use, body mass index, ethnicity, diabetes mellitus, and cardiovascular disease. 
HRT and those without HRT was small $(0.14 \%$ vs $0.11 \%$, or $0.03 \%$ ). The magnitude of absolute difference was similar to the difference in rate of SAH observed in women with active cigarette smoking and those with no history of smoking $(0.14 \%$ vs $0.11 \%$, or $0.03 \%)$ in the WHI study. The clinical significance of such differences may not be adequate for acceptance of new therapeutic interventions for prevention of SAH that are associated with increased cost and risk, but may be of value in abstinence strategies that are associated with cost reduction, such as avoidance of HRT and cigarette smoking.

Endothelial and vascular smooth muscle cells are abundant with both estrogen receptor- $\alpha$ and estrogen receptor- $\beta .^{12,35}$ Estrogens in both human studies and experimental models cause a significant alteration in vascular tone. ${ }^{23}$ The antiinflammatory and vascular relaxation effect of estrogen is not seen after a prolonged period of estrogen deprivation, ${ }^{27,29}$ which may have a common occurrence in WHI participants who were 50-79 years of age and had a large interval between menopause and initiation of HRT. However, the mechanism underlying the increased risk associated with HRT is probably related to the complex relationship between the ratio of different types of estrogen receptors present in vascular smooth muscles and context specificity of the estrogen hormones. ${ }^{14}$ Estrogens produce reactive oxygen species by increasing mitochondrial activity and redox cycling of estrogen metabolites, leading to activation of proinflammatory pathways. ${ }^{37}$ An increase in plasma fibrinolytic activity primarily related to a significant increase in tissue-type plasminogen activator and a decrease in plasminogen activator inhibitor Type 1 has been observed in women receiving HRT. ${ }^{9,32,36}$ Cerebral vasodilation ${ }^{4}$ and transient elevation in systemic blood pressure $^{31}$ associated with HRT may additionally contribute to risk of SAH in postmenopausal women.

The results were obtained from a population 50-79 years of age, with only $28 \%$ of these women being between 50-59 years old. ${ }^{16}$ Younger and/or more recently menopausal women may have a better risk-benefit ratio than older or remotely menopausal women. ${ }^{10}$ The age distribution and delay in initiation of HRT after menopause may not accurately reflect the current practice. The class effects associated with particular estrogen and progesterone types were not investigated. Conjugated equine estrogens and $17 \beta$-estradiol differ with respect to their source and composition, pharmacokinetic and metabolic profile, and total estrogenic potency. ${ }^{6}$ For progesterone, medroxyprogesterone acetate and norethisterone acetate have different pharmacokinetic profiles and different activities on steroid receptors. Therefore, generalization of results pertaining to certain HRTs must be undertaken with caution. The duration of treatment is another issue because of data suggesting that cardiovascular benefit of HRT may require at least 5 years of treatment. ${ }^{6}$

\section{Conclusions}

Postmenopausal women, particularly those at risk for SAH due to presence of unruptured aneurysms, family history, or cardiovascular risk factors, should be counseled against use of HRT. If the HRT use is medically necessary in women who have risk factors for $\mathrm{SAH}$, an estrogen and progesterone combination may be preferable rather than unopposed estrogen preparations. ${ }^{21}$

\section{Acknowledgments}

The manuscript was prepared using the WHI Observational Study Research Materials obtained from the National Heart, Lung, and Blood Institute Biologic Specimen and Data Repository Information Coordinating Center. The manuscript does not necessarily reflect the opinions or views of the WHI Observational Study or the National Heart, Lung, and Blood Institute.

\section{References}

1. Algra AM, Klijn CJ, Helmerhorst FM, Algra A, Rinkel GJ: Female risk factors for subarachnoid hemorrhage: a systematic review. Neurology 79:1230-1236, 2012

2. Anderson GL, Manson J, Wallace R, Lund B, Hall D, Davis $\mathrm{S}$, et al: Implementation of the Women's Health Initiative study design. Ann Epidemiol 13 (9 Suppl):S5-S17, 2003

3. Andreasen TH, Bartek J Jr, Andresen M, Springborg JB, Romner B: Modifiable risk factors for aneurysmal subarachnoid hemorrhage. Stroke 44:3607-3612, 2013

4. Bain CA, Walters MR, Lees KR, Lumsden MA: The effect of HRT on cerebral haemodynamics and cerebral vasomotor reactivity in post-menopausal women. Hum Reprod 19:2411-2414, 2004

5. Brett KM, Reuben CA: Prevalence of estrogen or estrogenprogestin hormone therapy use. Obstet Gynecol 102:12401249,2003

6. Burger H: Hormone replacement therapy in the post-Women's Health Initiative era. Report a a meeting held in Funchal, Madeira, February 24-25, 2003. Climacteric 6 (Suppl 1):11-36, 2003

7. Curb JD, McTiernan A, Heckbert SR, Kooperberg C, Stanford J, Nevitt M, et al: Outcomes ascertainment and adjudication methods in the Women's Health Initiative. Ann Epidemiol 13 (9 Suppl):S122-S128, 2003

8. de Rooij NK, Linn FH, van der Plas JA, Algra A, Rinkel GJ: Incidence of subarachnoid haemorrhage: a systematic review with emphasis on region, age, gender and time trends. J Neurol Neurosurg Psychiatry 78:1365-1372, 2007

9. Gilabert J, Estellés A, Cano A, España F, Barrachina R, Grancha $S$, et al: The effect of estrogen replacement therapy with or without progestogen on the fibrinolytic system and coagulation inhibitors in postmenopausal status. Am J Obstet Gynecol 173:1849-1854, 1995

10. Harman SM: Menopausal hormone treatment cardiovascular disease: another look at an unresolved conundrum. Fertil Steril 101:887-897, 2014

11. Johnston SC, Colford JM Jr, Gress DR: Oral contraceptives and the risk of subarachnoid hemorrhage: a meta-analysis. Neurology 51:411-418, 1998

12. Kim KH, Bender JR: Membrane-initiated actions of estrogen on the endothelium. Mol Cell Endocrinol 308:3-8, 2009

13. Korja M, Lehto H, Juvela S: Lifelong rupture risk of intracranial aneurysms depends on risk factors: a prospective Finnish cohort study. Stroke 45:1958-1963, 2014

14. Kumar S, Lata K, Mukhopadhyay S, Mukherjee TK: Role of estrogen receptors in pro-oxidative and anti-oxidative actions of estrogens: a perspective. Biochim Biophys Acta 1800:1127-1135, 2010

15. Langer RD, White E, Lewis CE, Kotchen JM, Hendrix SL, Trevisan M: The Women's Health Initiative Observational Study: baseline characteristics of participants and reliability of baseline measures. Ann Epidemiol 13 (9 Suppl):S107S121, 2003 
16. Lemay A: The relevance of the Women's Health Initiative results on combined hormone replacement therapy in clinical practice. J Obstet Gynaecol Can 24:711-715, 2002

17. Li C, Samsioe G, Lidfelt J, Nerbrand C, Agardh CD: Women's Health in Lund Area S: Important factors for use of hormone replacement therapy: a population-based study of Swedish women. The Women's Health in Lund Area (WHILA) Study. Menopause 7:273-281, 2000

18. Lindegård B, Hillbom M, Brody S: High-dose estrogenprogestagen oral contraceptives: a risk factor for aneurysmal subarachnoid hemorrhage? Acta Neurol Scand 76:37-45, 1987

19. Longstreth WT, Nelson LM, Koepsell TD, van Belle G: Subarachnoid hemorrhage and hormonal factors in women. A population-based case-control study. Ann Intern Med 121:168-173, 1994

20. Lucas R, Barros H: Life prevalence and determinants of hormone replacement therapy in women living in Porto, Portugal. Maturitas 57:226-232, 2007

21. Main C, Knight B, Moxham T, Gabriel Sanchez R, Sanchez Gomez LM, Roqué i Figuls M, et al: Hormone therapy for preventing cardiovascular disease in post-menopausal women. Cochrane Database Syst Rev 4:CD002229, 2013

22. Mhurchu CN, Anderson C, Jamrozik K, Hankey G, Dunbabin D: Hormonal factors and risk of aneurysmal subarachnoid hemorrhage: an international population-based, case-control study. Stroke 32:606-612, 2001

23. Miller VM, Duckles SP: Vascular actions of estrogens: functional implications. Pharmacol Rev 60:210-241, 2008

24. Nelson HD, Humphrey LL, Nygren P, Teutsch SM, Allan JD: Postmenopausal hormone replacement therapy: scientific review. JAMA 288:872-881, 2002

25. Pedersen AT, Lidegaard O, Kreiner S, Ottesen B: Hormone replacement therapy and risk of non-fatal stroke. Lancet 350:1277-1283, 1997

26. Petitti DB, Wingerd J: Use of oral contraceptives, cigarette smoking, and risk of subarachnoid haemorrhage. Lancet 2:234-235, 1978

27. Pinna C, Cignarella A, Sanvito P, Pelosi V, Bolego C: Prolonged ovarian hormone deprivation impairs the protective vascular actions of estrogen receptor alpha agonists. Hypertension 51:1210-1217, 2008

28. Qureshi AI, Suarez JI, Parekh PD, Sung G, Geocadin R, Bhardwaj A, et al: Risk factors for multiple intracranial aneurysms. Neurosurgery 43:22-27, 1998

29. Suzuki S, Brown CM, Dela Cruz CD, Yang E, Bridwell DA, Wise PM: Timing of estrogen therapy after ovariectomy dictates the efficacy of its neuroprotective and antiinflammatory actions. Proc Natl Acad Sci U S A 104:6013-6018, 2007

30. Tada Y, Wada K, Shimada K, Makino H, Liang EI, Muraka- mi S, et al: Estrogen protects against intracranial aneurysm rupture in ovariectomized mice. Hypertension 63:13391344,2014

31. Tuomikoski P, Haapalahti P, Sarna S, Ylikorkala O, Mikkola TS: Vasomotor hot flushes and 24-hour ambulatory blood pressure in normotensive women: A placebo-controlled trial on post-menopausal hormone therapy. Ann Med 42:334-343, 2010

32. Vehkavaara S, Silveira A, Hakala-Ala-Pietilä T, Virkamäki A, Hovatta O, Hamsten A, et al: Effects of oral and transdermal estrogen replacement therapy on markers of coagulation, fibrinolysis, inflammation and serum lipids and lipoproteins in postmenopausal women. Thromb Haemost 85:619-625, 2001

33. Wassertheil-Smoller S, Hendrix SL, Limacher M, Heiss G, Kooperberg C, Baird A, et al: Effect of estrogen plus progestin on stroke in postmenopausal women: the Women's Health Initiative: a randomized trial. JAMA 289:2673-2684, 2003

34. The Women's Health Initiative Study Group: Design of the Women's Health Initiative clinical trial and observational study. Control Clin Trials 19:61-109, 1998

35. Young AM, Karri SK, Ogilvy CS: Exploring the use of estrogen \& progesterone replacement therapy in subarachnoid hemorrhage. Curr Drug Saf 7:202-206, 2012

36. Zegura B, Guzic-Salobir B, Sebestjen M, Keber I: The effect of various menopausal hormone therapies on markers of inflammation, coagulation, fibrinolysis, lipids, and lipoproteins in healthy postmenopausal women. Menopause 13:643-650, 2006

37. Zegura B, Keber I, Sebestjen M, Koenig W: Double blind, randomized study of estradiol replacement therapy on markers of inflammation, coagulation and fibrinolysis. Atherosclerosis 168:123-129, 2003

\section{Author Contributions}

Conception and design: all authors. Acquisition of data: Qureshi, Malik, Saeed, Suri. Analysis and interpretation of data: all authors. Drafting the article: all authors. Critically revising the article: Qureshi, Malik, Defillo, Sherr, Suri. Reviewed submitted version of manuscript: all authors. Approved the final version of the manuscript on behalf of all authors: Qureshi. Statistical analysis: Qureshi, Malik, Saeed, Suri. Study supervision: Qureshi, Suri.

\section{Correspondence}

Adnan I. Qureshi, Zeenat Qureshi Stroke Institute, 519 2nd St. N., St. Cloud, MN 56303.email: qureshai@gmail.com. 